JURNAL NOMINAL / VOLUME VI NOMOR 2 / TAHUN 2017

\title{
PENGARUH KOMITE AUDIT, UKURAN PERUSAHAAN, UKURAN KAP TERHADAP TINGKAT KESELARASAN LAPORAN TAHUNAN DENGAN RERANGKA INTEGRATED REPORTING
}

\author{
Rudy Ahmad \\ Akuntansi Universitas Negeri Yogyakarta \\ nuansa.rudy@gmail.com \\ Ratna Candra Sari \\ Staf Pengajar Jurusan Pendidikan Akuntansi Universitas Negeri Yogyakarta
}

\begin{abstract}
Abstrak: Pengaruh Komite Audit, Ukuran Perusahaan, Ukuran KAP terhadap Tingkat Keselarasan Laporan Tahunan dengan Rerangka Integrated Reporting. Penelitian ini bertujuan untuk mengetahui pengaruh Komite Audit, Ukuran Perusahaan dan Ukuran KAP terhadap Tingkat Keselarasan Laporan Tahunan dengan Rerangka Integrated Reporting (IR). Pemilihan variabel dalam penelitian ini karena penelitian sebelumnya menunjukkan hasil yang inkonsiten. Populasi dalam penelitian ini adalah perusahaan sektor pertambangan yang terdaftar di BEI periode 2014-2015. Metode pengambilan sampel menggunakan metode purposive sampling sehingga diperoleh sebanyak 64 sampel selama dua tahun pengamatan. Teknik pengumpulan data menggunakan metode dokumentasi. Uji analisis data dalam penelitian ini adalah analisis statistik deskriptif, uji asumsi klasik dan uji hipotesis.Hasil penelitian yang telah dilakukan menunjukkan bahwa Komite Audit, Ukuran Perusahaan dan Ukuran KAP baik secara parsial maupun simultan berpengaruh signifikan terhadap Tingkat Keselarasan Laporan Tahunan dengan Rerangka IR.
\end{abstract}

Kata Kunci: Rerangka Integrated Reporting (IR), Komite Audit, Ukuran Perusahaan, Ukuran KAP.

\begin{abstract}
The Effect of Audit Committee, Firm Size, KAP Size on the Alignment Level of Annual Report with Integrated Reporting Framework. This study aims to determine the effect of Audit Committee,Firm Size, KAP Size on the Alignment Level of Annual Report with Integrated Reporting Framework. Selection of variables in this study because previous studies have shown incosistent results. Population in this study is mining sector companies listed in IDX period 2014-2015. Sampling method using purposive sampling method so the data analyzed research amounted to 64 sample for two years. Data analysis technique documentation method. Data analysis test in this study are descriptive analistical analysis, classical assumption test and hypothesis test. The results of the research have shown that Audit Committee, Firm Size and KAP Size either partially or simultaneously have significant effect on the Alignment Level of Annual Report with IR Framework.
\end{abstract}

Keywords: Integrated Reporting (IR) Framework, Committee Audit, Firm Size, KAP Size.

\section{PENDAHULUAN}

Pada tahun 2008 masyarakat dunia dikejutkan dengan krisis keuangan global yang melanda Amerika Serikat. Salah satu penyebabnya adalah pelaporan perusahaan yang hanya berorientasikan pada kepentingan shareholder dan tidak memperhatikan kepentingan stakeholders lain. Pandangan yang berpusat pada shareholder dianggap sebagai penyumbang utama terjadinya krisis keuangan global tahun 2008 (Stiglitz, 2009). Hal ini memunculkan desakan kepada perusahaan di dunia agar tidak hanya melaporkan laporan keuangan tetapi juga laporan non keuangan.

Perkembangan laporan non keungan perusahaan diawali dengan 


\section{JURNAL NOMINAL / VOLUME VI NOMOR 2 / TAHUN 2017}

munculnya laporan tanggung jawab sosial perusahaan atau Corporate Social Responsibility (CSR). Konsep tersebut berkembang lagi menjadi laporan berkelanjutan atau Sustainability Report $(S R)$ Namun, banyak perusahaan memisahkan antara laporan SR dengan laporan tahunan perusahaan sehingga tidak disediakan untuk memfasilitasi pemahaman stakeholders dan menjadikan berkurangnya kemanfaatan dari laporan tersebut (Utami, 2016). ACCA \& Eufosif, (2013) menyatakan bahwa saat ini laporan non keuangan tidak cukup relevan dan informasi keuangan akan lebih baik diintegrasikan dengan laporan keuangan. Pada tahun 2010 terbentuklah International Integrated Reporting Council (IIRC) yang mengembangkan laporan terintegrasi atau Integrated Reporting (IR). Pedoman yang digunakan dalam IR adalah IR Framework.

Salah satu negara pelopor penerapan IR adalah Afrika Selatan melalui pedoman King III, yaitu perusahaan-perusahaan yang terdaftar di Bursa Efek Johannesburg diwajibkan menerbitkan integrated reporting sejak tahun 2010. Churet et al. (2014) melakukan penelitian pada 2000 perusahaan yang terdaftar pada $S \& P$ Global Boad Market Index periode 2011-2012 terkait penerapan IR Hasil menunjukkan bahwa terdapat peningkatan penerapan IR oleh perusahaan dari tahun sebelumnya.
IR memberikan manfaat bagi perusahaan untuk lebih transparan dalam pelaporan. PricewaterhouseCoopers (2013) dalam artikelnya menjelaskan perusahaanperusahaan yang menggunakan konsepkonsep IR dimungkinan menghasilkan laporan yang lebih transparan dan dapat meningkatkan akses perusahaan mendapatkan modal. Hal ini diperkuat pendapat Azam et al. (2011); Cheng et al. (2014): Serefeim (2015) dalam (Utami, 2016) bahwa IR memiliki manfaat untuk meningkatkan transparansi di dalam operasi perusahaan, dengan meningkatnya transparansi maka akan meningkatkan kepercayaan stakeholder.

Penelitian-penelitian terdahulu terkait tingkat pengungkapan laporan perusahaan berdasarkan CSR maupun SR telah banyak dilakukan, namun menujukkan hasil yang beragam. Penelitian yang dilakukan oleh Nasir dkk. (2014), Edo \& Hadiprajitno (2013) menunjukkan bahwa Komite Audit berpengaruh negatif terhadap Luas Pengungkapan Tanggung Jawab Sosial. Adapun penelitian oleh Ariningtika \& Kiswara (2013) dan Handajani dkk. (2010) menunjukkan bahwa Komite Audit berpengaruh positif terhadap Luas Pengungkapan Tanggung Jawab Sosial

Ukuran Perusahaan dianggap mempunyai pengaruh terhadap pengungkapan CSR atau SR. Hasil 


\section{JURNAL NOMINAL / VOLUME VI NOMOR 2 / TAHUN 2017}

penelitian yang dilakukan Sembiring (2005), Nur \& Priantinah (2012) dan Kurniawati (2013) menemukan bahwa Ukuran Perusahaan berpengaruh positif terhadap Sustainability Report (SR). Namun berbeda dengan penelitian oleh Fr. Reni (2006), Sari dkk. (2013) dan Nasir dkk. (2014) yang menunjukkan Ukuran Perusahaan berpengaruh negatif terhadap CSR.

Hubungan antara Ukuran KAP dan pengungkapan laporan perusahaan juga menunjukkan hasil yang beragam. Penelitian oleh Cafferman dan Cooke (2000) dalam Huda (2015) dan Huda (2015) menunjukkan Reputasi Auditor KAP berpengaruh terhadap Tingkat Pengungkapan Sukarela Laporan Tahunan. Akan tetapi berbeda dengan hasil penelitian Alaseed (2005) dalam Lukita (2015) dan Lukita (2015) menyatakan Ukuran KAP tidak berpengaruh terhadap Pengungkapan Sukarela.

Perbedaan hasil penelitian dapat disebakan karena perbedaan sampel dan pedoman penelitian yang digunakan. Hal ini mendorong penulis untuk menguji kembali apakah Komite Audit, Ukuran Perusahaan, Ukuran KAP cukup efektif dalam meningkatkan transparansi dan kualitas pelaporan. Adapun pengukurannya menggunakan laporan tahunan dengan rerangka IR.
Penelitian mengenai IR di Indonesia belum banyak dilakukan karena IR merupakan konsep yang masih tergolong baru. Selain itu, pemerintah belum mengeluarkan kebijakan yang mewajibkan perusahaan publik di Indonesia untuk melakukan IR sehingga masih bersifat sukarela. Namun, usaha untuk mengarah penerapan IR mulai ada, seperti pada acara Simposium Nasional Akuntansi (SNA) ke XVII tahun 2014 yang membahas mengenai "Peranan Akuntan dalam Pembangunan Berkelanjutan Melalui Pelaporan Terintegrasi”. Ini merupakan salah satu wujud persiapan untuk menuju ke arah penerapan IR di Indonesia.

Tujuan dalam penelitian ini adalah untuk mengetahui pengaruh variabel Komite Audit, Ukuran Perusahaan dan Ukuran KAP terhadap Tingkat Keselarasan Laporan Tahunan dengan IR pada Perusahaan Pertambangan yang Terdaftar di Bursa Efek Indonesia (BEI) Periode 2014-2015. Alasan pemilihan perusahaan pertambangan, karena perusahaan pertambangan merupakan salah satu perusahaan ekstraktif, yang menurut Hackston \& Milne (1996) dalam Sembiring (2005) lebih mungkin mengungkapkan informasi perusahaan diandingan industri yang lain. 


\section{METODE PENELITIAN}

\section{Jenis Penelitian}

Jenis penelitian yang dilakukan merupakan penelitian kuantitatif. Penelitian ini menggunakan penelitian kausal komparatif yaitu penelitian yang bertujuan untuk mengetahui hubungan Komite Audit, Ukuran Perusahaan dan Ukuran KAP terhadap Tingkat Keselarasan Laporan Tahunan dengan Rerangka IR pada Perusahaan Pertambangan Tahun 20142015.

\section{Tempat dan Waktu Penelitian}

Penelitian ini menggunakan data sekunder, yaitu data primer yang yang telah diolah lebih lanjut dan disajikan baik oleh pihak pengumpul data primer atau oleh pihak-pihak lain misalnya dalam bentuk tabel-tabel atau diagram-diagram (Umar, 2011: 42). Data yang digunakan adalah laporan tahunan pada perusahaan pertambangan yang terdaftar di BEI periode tahun 2014-2015 yang didownload pada situs BEI yaitu www.idx.ac.id. Waktu penelitian dilakukan pada bulan JanuariJuli 2017.

\section{Definisi Operasional Variabel}

Variabel Dependen

Tingkat Keselarasan Laporan Tahunan dengan Rerangka IR

Integrated Reporting (IR) merupakan suatu komunikasi singkat mengenai bagaimana strategi organisasi, tata kelola, performa, dan prospek organisasi dapat menciptakan nilai jangka pendek, jangka menengah, dan jangka panjang (International Integrated Reporting Council's, 2013). Tingat Keselarasan Laporan Tahunan dengan Rerangka IR merupakan mengukur kesesuaian antara laporan tahunan yang diterbitkan oleh perusahaan dengan Rerangka IR. Pengukuran IR menggunakan Content Element yang terdapat di Rerangka IR. Content Element terdiri dari Ikhtisiar Organisasi dan Model Bisnis (tujuh item), Operating Context (sembilan item), Tujuan Strategis dan Strategi untuk Mencapainya (tujuh item), Tata Kelola (delapan item), Kinerja (sepuluh item), Future Outlook (tujuh item). Setiap indikator yang diungkapkan akan diberi skor 1 dan skor 0 jika tidak diungkapkan.

$$
\text { Content element }=\frac{\text { Total item }}{48 \text { item }}
$$

\section{Variabel Independen}

Komite Audit

Komite Audit berfungsi untuk melakukan pengawasan terhadap aktivitas perusahaan, sehingga manajemen perusahaan tidak melakukan penyelewengan. Menurut ketentuan, anggota Komite Audit perusahaan minimal terdiri dari tiga orang. Keberadaan Komite Audit diharapkan dapat meningkatkan pengawasan terhadap manajemen yang lebih efektif dan efisien serta mendorong 
peningkatan pengungkapan informasi secara menyeluruh kepada pemangku kepentingan. Pengukuran variabel Komite Audit dilakukan dengan memberikan skor satu (1) bagi perusahaan yang memiliki anggota komite audit tiga orang atau lebih, sedangkan skor nol (0) bagi yang anggota komite audit kurang dari tiga orang.

Jumlah Komite Audit $\geq 3$ mendapat skor 1

Jumlah Komite Audit $<3$ mendapat skor 0

Ukuran Perusahaan

Ukuran perusahaan merupakan gambaran mengenai besar kecilnya suatu perusahaan. Perusahaan besar pada umumnya memiliki jumlah aktiva yang besar sehingga dapat menarik investor untuk melakukan investasi pada perusahaan tersebut. Perusahaan besar akan mengungkapkan informasi yang lebih banyak karena menghadapi tekanan politis dari berbagai pemangku kepentingan yang juga lebih besar (Sinaga, 2011). Pengukuran variabel Ukuran Perusahaan menggunakan log natural dari total asset (Klapper \& Love, 2002).

$$
S I Z E=\operatorname{Ln}(\text { Total Asset })
$$

\section{Ukuran KAP}

Menurut SPAP (Standar Profesi Akuntan Publik) pengertian Kantor Akuntan Publik merupakan organisasi yang melaksanakan jasa profesional yang dicakup oleh Standar Profesional Akuntan Publik dan meliputi patner, dan staf profesional. KAP berdasarkan ukurannya dapat dibedakan menjadi dua yaitu KAP berukuran besar (Big four accounting firm) dan KAP berukuran kecil (non big four accounting firm). KAP besar dianggap mempunyai kualitas dan kuantitas sumber daya yang lebih baik sehingga akan berpengaruh pada kualitas jasa yang dihasilkan. Pengukuran variabel Ukuran KAP dilakukan dengan memberikan skor satu (1) bagi perusahaan pertambangan yang menggunakan jasa KAP big four, sedangkan skor nol (0) bagi perusahaan yang menggunakan KAP non big four.

$\mathrm{KAP}$ big four $=$ skor 1

KAP bukan big four $=$ skor 0

\section{Teknik Analisis Data}

Metode analisis yang digunakan dalam penelitian ini terdiri dari analisis statistik deskriptif, uji asumsi klasik dan uji hipotesis. Uji asumsi klasik terdiri dari uji normalitas, uji multikolineritas, uji hiteroskedastisitas, dan autokorelasi. Uji hipotesis terdiri dari uji $\mathrm{F}$ (f-test), uji $\mathrm{t}$ ( $t$ test), dan uji Determinasi $\left(\mathrm{R}^{2}\right)$.

Model regresi

$$
I R=\alpha+\beta_{1} X_{1}+\beta_{2} X_{2}+\beta_{3} X_{3}+e
$$

Keterangan:

IR : Integrated Reporting

$\alpha \quad$ : Nilai konstanta

$\beta_{1}-\beta_{3}$ : Koefisien regresi

$X_{1} \quad$ : Komite Audit

$X_{2} \quad$ : Ukuran Perusahaan 
JURNAL NOMINAL / VOLUME VI NOMOR 2 / TAHUN 2017

$X_{3} \quad$ : Ukuran KAP

$e \quad:$ Koefisien gangguan / error

HASIL PENELITIAN DAN

PEMBAHASAN

Hasil Analisis Deskriptif

Tabel 1. Statistik Deskriptif

Hasil dari perhitungan berdasarkan

\begin{tabular}{lllll}
\hline Var & Min. & Max. & Mean & $\begin{array}{c}\text { Std. } \\
\text { Dev. }\end{array}$ \\
\hline IR & 0,42 & 0,96 & 0,7859 & $\begin{array}{l}0,1348 \\
5\end{array}$ \\
\hline KOA & 0,00 & 1,00 & 0,9375 & 0,2439 \\
U & & & & 8 \\
\hline SIZE & 25,86 & 32,05 & 29,161 & 1,4758 \\
& & & 7 & 9 \\
\hline UKAP & 0,00 & 1,00 & 0,5000 & 0,5039 \\
& & & & 5 \\
\hline
\end{tabular}

Tabel 1 diperoleh Tingkat Keselarasan Laporan Tahunan dengan Rerangka IR memiliki nilai terendah 0,42 yang dimiliki oleh PT Perdana Karya Perkasa Tbk, nilai tertinggi 0,96 dimiliki oleh PT Vale Indonesia Tbk dan PT Timah (Persero) Tbk dan nilai rata-rata IR sebesar 0,7859. Komite Audit (KOAU) memiliki nilai minimal 0,00 dan nilai maksimum 1,00 serta nilai rata-rata 0,9375. Ukuran Perusahaan (SIZE) memiliki nilai minimum sebesar 25,86 , nilai maksimum sebesar 32,05 dan nilai rata-rata sebesar 29,1617. Selanjutnya Ukuran KAP (UKAP) memiliki nilai minimum 0,00 dan nilai maksimum 1,00, sedangkan nilai rata-rata menujukkan 0,5000 .

\section{Hasil Uji Asumsi Klasik \\ Uji Normalitas}

Tabel 1. Uji Normalitas

\begin{tabular}{ccl}
\hline Variabel & Probabilitas & Keterangan \\
\hline $\begin{array}{c}\text { Residual } \\
\text { Regresion }\end{array}$ & 0,419 & Normal \\
\hline
\end{tabular}

Sumber: data sekunder diolah

Hasil uji normarlitas menggunakan Kolmogrorov-Smirnov Test dengan probabilitas lebih dari 0,05 menunjukkan nilai signifikan sebesar 0,419. Berdasarkan hasil uji tersebut dapat disimpulkan bahwa model regresi dalam penelitian ini berdistribusi normal.

\section{Uji Multikolinieritas}

Tabel 2. Uji Multikolieritas

\begin{tabular}{lcrl}
\hline \multicolumn{1}{c}{ Var. } & VIF & Tol. & Keterangan \\
\hline KOA & 1,073 & 0,932 & $\begin{array}{l}\text { Tidak terjadi } \\
\text { multikolineritas }\end{array}$ \\
U & & & $\begin{array}{l}\text { Tidak terjadi } \\
\text { multikolineritas }\end{array}$ \\
\hline SIZE & 1,209 & 0,827 & \\
\hline UKAP & 1,289 & 0,776 & $\begin{array}{l}\text { Tidak terjadi } \\
\text { multikolineritas }\end{array}$
\end{tabular}

Sumber: data sekunder diolah

Hasil pada tabel 3 uji mulikolineritas menggunakan nilai Variance Inflation Factor (VIF) dan Tolerance menunjukkan bahwa pada variabel independen memiliki nilai VIF kurang dari 10 dan nilai tolerance lebih dari 0,1. Maka dapat disimpulkan bahwa tidak terjadi multikolineritas antar variabel independen dan kontrol. 
JURNAL NOMINAL / VOLUME VI NOMOR 2 / TAHUN 2017

Uji Heteroskedastisitas

Tabel 3. Uji Heteroskedastisitas

\begin{tabular}{cll}
\hline Var. & Sig. & \multicolumn{1}{c}{ Keterangan } \\
\hline KOAU & 0,805 & $\begin{array}{l}\text { Tidak terjadi } \\
\text { heterokedastisitas }\end{array}$ \\
\hline SIZE & 0,942 & $\begin{array}{l}\text { Tidak terjadi } \\
\text { heterokedastisitas }\end{array}$ \\
\hline UKAP & 0,780 & $\begin{array}{l}\text { Tidak terjadi } \\
\text { heterokedastisitas }\end{array}$ \\
\hline
\end{tabular}

Sumber: data sekunder diolah

Hasil uji heteroskedastisitas yang menggunakan metode Spearman's rho menunjukkan bahwa nilai semua variabel independen memiliki signifikansi di atas 0,05 yang berarti tidak terdapat gajala heteroskedastisitas.

\section{Uji Autokorelasi}

Tabel 4. Uji Autokorelasi

\begin{tabular}{|l|l|}
\hline Asymp. Sig. & \multicolumn{1}{|c|}{ Keterangan } \\
\hline 0,450 & $\begin{array}{l}\text { Tidak terjadi } \\
\text { autokorelasi }\end{array}$ \\
\hline
\end{tabular}

Sumber: data sekunder diolah

Uji autokorelasi dilakukan menggunakan uji Run-test. Hasil perhitungan diperoleh nilai signifikansi sebesar 0,450 (di atas 0,05). Berdasarkan hasil tersebut, maka dapat disimpulkan bahwa model regresi tidak terjadi autokorelasi.

\section{Uji Hipotesis}

Tabel 6. Hasil Uji t terhadap IR

\begin{tabular}{lllc}
\hline \multicolumn{1}{c}{ Var. } & t $_{\text {hitung }}$ & Sig. & Hasil \\
\hline KOMAU & 2,476 & 0,016 & Didukung \\
\hline SIZE & 5,370 & 0,000 & Didukung \\
\hline UKAP & 4,862 & 0,000 & Didukung \\
\hline
\end{tabular}

Sumber: data sekunder diolah
Tabel 7. Koefisien Determinasi

\begin{tabular}{cccc}
\hline Model & $\mathbf{R}$ & $\begin{array}{l}\mathbf{R} \\
\text { Square }\end{array}$ & $\begin{array}{l}\text { Ad. } \mathbf{R} \\
\text { Square }\end{array}$ \\
\hline 1 & 0,300 & 0,090 & 0,075 \\
\hline 1 & 0,563 & 0,317 & 0,306 \\
\hline 1 & 0,525 & 0,276 & 0,264 \\
\hline 1 & 0,675 & 0,455 & 0,428 \\
\hline
\end{tabular}

Sumber: data sekunder diolah

Tabel 8. Hasil Uji F

\begin{tabular}{cccc}
\hline Model & $\mathbf{F}_{\text {hitung }}$ & Sig. & Hasil \\
\hline Regresi & 16,704 & 0,000 & Didukung \\
\hline \multicolumn{4}{l}{ Sumber: data sekunder diolah }
\end{tabular}

\section{Pembahasan}

\section{Hipotesis Pertama}

Komite Audit mempunyai nilai $\mathrm{t}$ hitung sebesar 2,318 dan nilai signifikansi (p-value) sebesar 0,000. Karena nilai signifikansi lebih kecil dari 0,05 $(0,000<$ 0,05), maka disimpulkan bahwa Komite Audit berpengaruh terhadap Tingkat Keselarasan Laporan Tahunan dengan Rerangka IR sehingga H2 didukung. Nilai $\mathrm{R}^{2}$ sebesar 0,090 memiliki arti bahwa $9 \%$ variabel Komite Audit dapat dijelaskan oleh variabel Tingkat Keselarasan Laporan Tahunan dengan Rerangka IR, sedangkan sisanya $91 \%$ dijelaskan oleh faktor lain.

Komite Audit mempunyai peran dalam pengawasan terhadap aktivitas perusahaan sehingga manajemen tidak akan melakukan tindakan penyelewengan. Komite Audit juga dapat menunjukkan tugasnya dalam meminimaslisir agency problem. Prinsip responsibilitas yang mengarahkan perusahaan untuk memberikan informasi yang sebenarnya 


\section{JURNAL NOMINAL / VOLUME VI NOMOR 2 / TAHUN 2017}

dapat dijalankan oleh Komite Audit. Fungsi

Komite Audit memberikan dorongan kepada manajemen untuk dapat bekerja lebih efektif dan efisien sehingga mendorong pengungkapan informasi perusahaan, termasuk laporan tahunan perusahaan yang sesuai dengan IR.

Penelitian ini sejalan dengan penelitian yang dilakukan oleh Ahmed $\mathrm{H}$. \& Abdifatah (2015) dan Ahmed \& Anifowose (2016), yang menyatakan bahwa Komite Audit mempunyai pengaruh terhadap Laporan Perusahaan yang Terintegrasi. Sementara itu, hasil penelitian ini berbeda dengan Handajani (2010), Ariningtika \& Kiswara (2013) dan Habbash (2015) yang menyatakan Komite Audit tidak berpengaruh terhadap Tingkat Pengungkapan Laporan Perusahaan yang menggunakan SR.

\section{Hipotesis Kedua}

Nilai $\mathrm{t}$ hitung pada tabel 6 yang diperoleh sebesar 5,370 dan nilai signifikansi sebesar 0,000. Oleh karena nilai signifikansi lebih kecil dari $0,05(0,00$ $>0,05)$, maka dapat disimpulkan bahwa Ukuran Perusahaan berpengaruh terhadap Tingkat Keselarasan Laporan Tahunan dengan Rerangka IR sehingga hipotesis terdukung. Nilai $\mathrm{R}^{2}$ sebesar 0,317 memiliki arti bahwa $31,7 \%$ variabel Ukuran Perusahaan dapat dijelaskan oleh variabel Tingkat Keselarasan Laporan Tahunan dengan Rerangka IR, sedangkan sisanya $63 \%$ dijelaskan oleh faktor lain.

Perusahaan

pertambangan merupakan salah satu perusahaan ekstraktif yang kegiatannya mengambil dan memanfaatkan kekayaan alam. Menurut Hackston \& Milne (1996) dalam Sembiring (2005) menyatakan bahwa perusahaan yang memiliki aktivitas ekonomi yang memodifikasi lingkungan, seperti perusahaan ekstraktif, lebih mungkin mengungkapkan informasi perusahaan dibangkan industri yang lain. Teori agensi menjelaskan bahwa semakin besar suatu perusahaan maka memunculkan biaya keagenan yang semakin besar. Salah satu cara perusahaan besar untuk mengurangi biaya keagenan adalah dengan mengungkapkan informasi yang lebih luas, termasuk melalui pelaporan terintegrasi.

Penelitian ini mendukung penelitian yang dilakukan oleh Sembiring (2005), Nur \& Priantinah (2012) dan Kurniawati (2013) yang menyatakan Ukuran Perusahaan berpengaruh signifikan terhadap perusahaan yang mengungkapkan CSR. Hasil penelitian yang berbeda ditunjukkan oleh Fr. Reni (2006), Sari dkk. (2013) dan Nasir dkk. (2014) yang menyatakan Ukuran Perusahaan tidak berpengaruh terhadap Pengungkapan CSR. 


\section{JURNAL NOMINAL / VOLUME VI NOMOR 2 / TAHUN 2017}

\section{Hipotesis Ketiga}

Hasil pada tabel 6 menunjukkan bahwa nilai t hitung yang diperoleh sebesar 4,862 dan nilai signifikansi sebesar 0,000 . Oleh karena nilai signifikansi yang lebih besar dari $0,05(0,000>0,05)$, dapat disimpulkan bahwa Ukuran KAP berpengaruh signifikan terhadap Tingkat Keselarasan Laporan Tahunan dengan Rerangka IR sehingga hipotesis didukung. Nilai $\mathrm{R}^{2} 0,276$ memliki arti $27,6 \%$ variabel Ukuran KAP dapat dijelaskan oleh variabel Tingkat Keselarasan Laporan Tahunan dengan Rerangka IR, sedangkan 72,4\% dijelaskan oleh faktor lain.

KAP yang berukuran besar cenderung lebih independen terhadap kliennya. Ukuran KAP yang besar dianggap dapat memberikan kualitas audit yang lebih tinggi karena memiliki reputasi yang tinggi. Kuantitas dan kualitas KAP besar dianggap lebih siap dan mampu dalam penerapan pelaporan terintegrasi. Kelebihan dari KAP big 4 yaitu memiliki kantor yang tersebar di seluruh dunia sedangkan KAP kecil menjalankan kegiatan audit hanya pada perusahaan lokal. KAP besar memiliki kemampuan untuk memberikan saran-saran kepada perusahaan dalam melakukan pengungkapan informasi perusahaannya, termasuk pelaporan terintegrasi.

Hasil penelitian ini sejalan dengan penelitian Cafferman dan Cooke (2000) dalam Huda (2015) dan Huda (2015) yang mana Reputasi Auditor KAP berpengaruh positif terhadap Tingkat Pengungkapan Sukarela Laporan Tahunan. Namun penelitian oleh Alaseed (2005) dalam Lukita (2015) dan Lukita (2015) menemukan bahwa Ukuran KAP tidak berpengaruh terhadap Tingkat Pengungkapan Sukarela.

\section{Hipotesis Keempat}

Hasil sesuai tabel 6 menunjukkan bahwa nilai $\mathrm{F}$ hitung sebesar 16,704 dan nilai signifikansi sebesar 0,000 . Oleh karena nilai signifikansi yang lebih besar dari $0,05(0,000>0,05)$, maka dapat disimpulkan bahwa secara bersama-sama variabel Komite Audit, Ukuran Perusahaan, dan Ukuran KAP berpengaruh signifikan terhadap tingkat keselarasan dengan rerangka IR, sehingga $\mathrm{H} 9$ didukung. Nilai $\mathrm{R}^{2}$ sebesar 0,455 yang artinya $45,5 \%$ variabel Tingkat Keselarasan Laporan Tahunan dengan Rerangka IR dapat dijelaskan oleh variabel Komite Audit, Ukuran Perusahaan dan Ukuran KAP, sedangkan sisanya 44,5\% dijelaskan oleh faktor lain.

Komite Audit, Ukuran Perusahaan dan ukuran KAP mempunyai peran dalam pengawasan keseluruhan aktivitas perusahaan. Masing-masing dari elemen tersebut saling bekerjasama dan mampu menyelesaikan permasalahan-permasa- 


\section{JURNAL NOMINAL / VOLUME VI NOMOR 2 / TAHUN 2017}

lahan yang ada di dalam perusahaan termasuk agency problem dan informasi asimetri. Konflik antara shareholder dangan stakeholder mampu ditekan. Selain itu, perusahaan mampu mewujudkan transparansi dan resposibilitas dalam pengungkapan informasi terhadap seluruh pemangku kepentingan, termasuk dalam laporan terintegrasi. Informasi tersebut memberikan gambaran keseluruhan perusahaan dalam menghasilkan nilai perusahaan dan menggambarkan kondisi perusahaan dalam jangka pendek, jangka menengah dan jangka panjang.

\section{KESIMPULAN DAN SARAN}

\section{Kesimpulan}

Berdasarkan serangkaian pengujian yang telah dilakukan, maka diperoleh hasil dan dapat ditarik kesimpulan sebagai berikut.

1. Komite Audit, Ukuran Perusahaan dan Ukuran KAP berpengaruh signifikan terhadap Tingkat Keselarasan Laporan Tahunan dengan Rerangka Integrated Reporting (IR).

2. Komite Audit, Ukuran Perusahaan dan Ukuran KAP secara bersama-sama berpengaruh signifikan terhadap Tingkat Keselarasan Laporan Tahunan dengan Rerangka Integrated Reporting (IR).

\section{Saran}

1. Saran bagi peneliti selanjutnya sebaiknya sampel yang dipilih lebih dari satu sektor. Periode pengamatan ditambah beberapa tahun sehingga akan dapat diketahui ada tidaknya pengaruh setiap tahunnya.

2.Penelitian selanjutnya dapat menambahkan variabel independen lain yang dianggap mempengaruhi Tingkat Keselarasan Laporan Tahunan terhadap IR. 3. Sebaiknya pada penelitian selanjutnya terkait pengukuran Tingkat Keselarasan Laporan Tahunan dengan Rerangka IR tidak hanya menggunakan Content Element tetapi juga menggunakan Guiding Principles.

\section{DAFTAR PUSTAKA}

ACCA, \& Eufosif. (2013, Juni 27). What do Investors Expect from NonFinancial Reporting? Diambil pada tanggal 26 Januari 2017. dari www.accaglobal.com

Ahmed, H. A., \& Anifowose, M. (2016). Audit Commitee and Integrated Reporting Practice: Does Internal Asurance Matter. Managerial Auditing Journal. 31(8/9). 915-948.

Ahmed, H., \& Abdifatah. (2015). The role of Audit Commitee Attributes in Intellectual Capital Disclosures: Evidence from Malaysia. Managerial Auditing Journal. 30(8/9). 756-784.

Ariningtika, P., \& Kiswara, E. (2013). Pengaruh Praktik Tata Kelola Perusahaan yang Baik terhadap Pengungkapan Lingkungan Perusahaan. Diponegora Journal of Accounting. 8. 
Churet, C., et al. (2014). Integrated Reporting, Quality of Management, and Financial Performance. Journal of Apllied Corporate Finance. 8.

Edo, Y. D., \& Hadiprajitno, P. B. (2013). Struktur Tata Kelola Perusahaan dan Luas Pengungkapan Tanggung Jawab Sosial Perusahaan. Diponegoro Journal of Accounting.

Fr. Reni, R. A. (2006). Pengungkapan Informasi Sosial dan Faktor-faktor yang Mempengaruhi Pengungkapan Informasi Sosial dalam Laporan Keuangan Tahunan (Studi Empiris pada Perusahaan-perusahaan yang Terdaftar di Bursa Efek Jakarta. Makalah SNA IX.

Habbash, M. (2015). Corporate Governance and Corporate Social Responsibility Disclosure : Evidence from Saudi Arabia. Journal of Social Responsibility. 10(9). 267-283.

Handajani, L. d. (2010). The Effect or Earnings Management and Corporate Governance Mechanism to Corporate Social Responsibility Disclosure. Makalah Simposium Nasional Akuntansi XII. Purwokerto.

Huda, A. N. (2015). Pengaruh Ukuran Perusahaan, Tingkat Profitabilitas dan Reputasi Kantor Akuntan Publik (KAP) terhadap Tingkat Pengungkapan Sukarela. Skripsi, 44.

International Integrated Reroting Council's. (2013). The International 〈IR> Framework. UK: IIRC.

Klapper, L., \& Love, I. (2002, April). Corporate Governance, Investor Protection, and Performance in emerging Market. World Bank Policy Research Working Paper.

Kurniawati, F. A. (2013). Pengaruh Profitabilitas, Leverage dan Ukuran Perusahaan terhadap Luar
Pengungkapan Tanggung Jawab Sosial Perusahaan Pertambangan di Bursa Efek Indonesia (BEI) Periode 2009-2012. Skripsi.

Lukita, A. (2015). Pengaruh Struktur Modal, Proporsi Kepemilikan Asing, dan Ukuran KAP terhadap Tingkat Pengungkapan Sukarela. Skripsi, 34.

PricewaterhouseCoopers. (2013). Point of View Integrated Reporting Going Beyond The Financial Results. United State. Diambil pada tanggal 19 Januari 2017. dari www.pwc.com

Nasir, dkk. (2014). Pengaruh Karakteristik Perusahaan dan Corporate Governance terhadap Pengungkapan Sustainability Report pada Perusahaan LQ45 yang Terdaftar. Jurnal Ekonomi. 15.

Nur, M., \& Priantinah, D. (2012). Analisis Faktor-Faktor yang Mempengaruhi Pengungkapan COrporate Social Responsibility di Indonesia (Studi Empiris pada Perusahaan Berkategori High Profile yang Listing di Bursa Efek Indonesia. Fakultas Ekonomi.

Sari, dkk. (2013, September). Pengaruh Kepemilikan Institusional, Komposisi Dewan Komisaris, Kinerja Perusahaan terhadap Luas Pengungkapan Corporate Social Responsibility di dalam Sustainability Report pada Perusahaan Manufaktur

Sembiring, E. R. (2005). Karakteristik Perusahaan dan Pengungkapan Tanggung Jawab Sosial: Studi Empiris pada Perusahaan yang Tercatat di Bursa Efek Jakarta. Simposium Nasional Akuntansi VIII. 379-395.

Stiglitz, J. (2009). The Financial Crisis of 2007/2008 and its Macro-economic Consequences. New York. NY: Columbia University. 